\title{
Axial stress-strain behaviour of pre-damaged square concrete column repaired with FRP jackets
}

\author{
Pengda $\mathrm{Li}^{*}$, Yingwu Zhou, Ningxu Han and Feng Xing \\ Guangdong provincial key laboratory of durability for marine civil engineering, Shenzhen University, Shenzhen, China
}

\begin{abstract}
This paper presents the results of an experimental study on the behaviour of pre-damaged concrete square columns that have been strengthened with carbon fibre-reinforced polymer (CFRP) wrap. Tests were conducted on 46 concrete columns involving variations of corner radius ratio, damage degree, and confinement pressure. The effect of corner radius on the main parameters of stress-strain curve for FRP strengthened pre-damaged specimens, such as compressive strength, strain capacity, initial elastic modulus, was investigated. The test results demonstrated that the efficiency of repairing damaged columns significantly depends on the corner radius ratio, the strength gain after FRP-strengthening decreases as the corner radius ratio reduces. Using those test data, new ultimate strength and ultimate strain model are proposed. The proposed models involved the effect of both corner radius and damage level, showing good agreement with the experimental results.
\end{abstract}

\section{Introduction}

Jacketing concrete columns with FRP has been identified as a highly effective way of restoring and enhancing the strength and ductility of columns damaged by catastrophic events such as earthquakes, blasts, and vehicle impact [1-3]. Previous researchers have made efforts on investigating the factors that affect the confinement effectiveness and indicated that the confinement effectiveness is governed by the properties of FRP and concrete, which mainly are the types of fibres, FRP thickness, concrete strength and the cross-sectional shape of concrete [4-9]. Particularly, Mirmiran et al. [10] suggested that square sections of FRP-confined concrete specimens are less effective in confining concrete than are their circular counterparts; Wu et al. [11] defined the corner radius ratio that is the ratio of the corner radius to the half breadth of the column, and stated that it is the single most important factor affecting the confinement across the cross-section, and this corner radius ratio should be as large as possible to achieve a better confinement. Afterwards, Wang and Wu [12] tested 108 CFRP-confined concrete short columns, studied the confinement effectiveness on the concrete specimen with varying corner radius, and the results validated that the corner radius is of great importance in relation to the level of applied confinement pressure. The strength gain of confined concrete columns is in direct proportion to the corner radius ratio. Most of the above-mentioned studies focused on the FRP retrofitting work that is FRP strengthened undamaged concrete. Apart from the retrofitting work, FRP as the confining material to repair damaged concrete that may be caused by a sudden overload such as earthquake, blast etc. is also in common.
However, few studies were reported for the stress-strain behaviour of FRP strengthened pre-damaged concrete, and most of the test results generally show that a highly effective restoration of the load capacity and ductility as retrofitting structures. Wu et al. [13] through experimental and analytical studies, first quantitatively investigated the existing damage effect on stress-strain behaviour of FRP repaired concrete columns, and reported that the damaged concrete should not be simply considered as another concrete with lower strength, and its properties, in terms of deformation capacity, initial elastic modulus, and confinement effectiveness, that are dependent on the existing pre-damage level. Correspondingly the model for FRP confined concrete with different pre-damage levels was proposed. In which the confinement effectiveness is the key parameters that govern the efficiency of repairing on damaged concrete column. However, in Wu et al.'s work [13] the effect of corner radius on damaged concrete has not been considered experimentally and discussed yet.

To address the test gap of that database and extend the application of $\mathrm{Wu}$ et al.'s stress-strain model [13], additional test on FRP confined pre-damaged concrete with varying corner radius were conducted and discussed in this work. These test results have filled the database for the expansion of $\mathrm{Wu}$ et al. model [13]. This paper, therefore, presents the improved Wu et al.'s model, and more accurate expressions for the ultimate strength and ultimate strain of FRP-strengthened pre-damaged concrete meanwhile considering corner radius effect were developed.

\footnotetext{
* Corresponding author: pdli.peter@szu.edu.cn
} 


\section{Corner radius effect and definition of concrete damage}

The aforementioned review clearly reveals that corner radius is of great importance on the stress-strain behaviour of FRP confined concrete [10-12]. As shown in Fig.1, the dashed lines show retrofitting work, where FRP jacket is constructed at point $\mathrm{O}$, and no damage has been involved before FRP strengthening. Previous study has indicated that the ultimate strength, ultimate strain, and the transition stress are depended on corner radius ratio, hence the stress-strain curve ended at point A, B, and C with the increasing corner radius ratio $(2 r / b)$. It is mainly related to the effectiveness of confinement [11,12], where $r$ is the corner radius and $b$ is the half-length of conium side. On the other hand, for repairing work, the typical stress-strain curve following the path O-P-D in Fig. 1, and then after the accidental overloading, the column is fully unloaded to zero stress (Point R), and then to repair the damaged concrete column. The reloading path after FRP strengthening will follow R-P'-A' until the new failure point (A') where FRP ruptures. The damage level to the column is depended on the unloading point along the stress-strain curve from $\mathrm{O}$ to $\mathrm{D}$. The analyses clearly reveal that a stress-strain model developed based on FRP retrofitted columns is, in principle, not applicable to FRP repaired columns, whereas the corner radius effect on the repair work of FRP confined concrete should be considered.

The definition of concrete damage $\delta$ in this work is same with that proposed by $\mathrm{Wu}$ et al. [13] which is the ratio of concrete strength loss to undamaged concrete strength, given:

$$
\delta=1-\frac{f_{c d}}{f_{c o}}
$$

where $f_{c o}$ and $f_{c d}$ are the strength of undamaged concrete (Point $\mathrm{P}$ ) and damaged concrete (Point $\mathrm{H}$ ), respectively. In this study, the effect of concrete damage combined with corner radius on the stress-strain behaviour of FRP confined concrete is investigated experimentally and analytically.

\section{Experimental programs}

\subsection{Specimen design}

All of the specimens were $150 \times 150 \mathrm{~mm}$ in cross-section and $300 \mathrm{~mm}$ in height but had different corner radii. The primary variables of this experiment were the corner radius, pre-damage level, and the thickness of the CFRP, respectively. Details of the test variables are provided in Table 1. A total of 46 specimens with varying corner radius $(0,15,30,45)$ were tested. Figure 2 shows the cross-section shape with corner radius variations, where three groups of specimens with corner radius 15, 30, 45 were strengthened by FRP, and the jackets thickness varied from two-ply to three-ply CFRP; another group specimens with sharp corner $(r=0)$ was used to define the damage level, the details will be shown in next section.

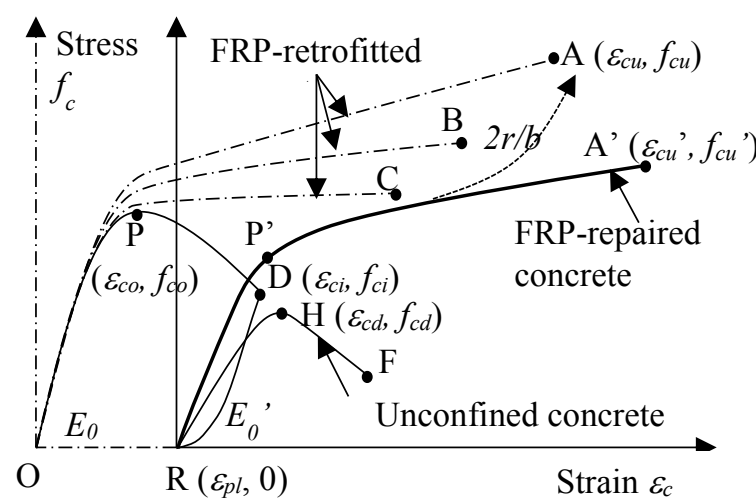

Fig. 1. Typical stress-strain curves
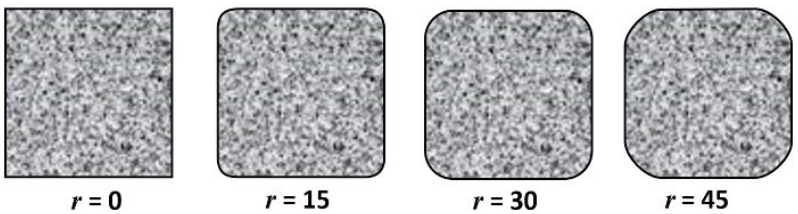

Fig. 2 Variation of corner radius

\subsection{Infliction of damage}

The pre-damage level was defined by inflicting precompression of the concrete columns to a load level that equals a certain percentage of the peak strength, $0,+85$, $100,-85,-75$ as shown in Fig. 3. The positive sign denotes that pre-compression load was applied before achieving the peak strength, whereas the negative sign denotes a load on the descending branch (Fig. 3). The damaging process was carried out in a $3000 \mathrm{kN}$ MTS compression machine under displacement control. For negative damage levels, the final applied load was calculated and monitored during a test as the actual peak load multiplied by the prescribed percentage. On the other hand, for positive damage level, the peak load was estimated from the mean peak loads of the specimens in the group that had negative damage level. When the pre-load reached a prescribed value, the concrete column was unloaded immediately. In this work, specimens with sharp corner are only used for defining pre-damage level, because previous research has shown that FRP confinement has little contribution on strength enhancement for sharp corner concrete column [12]. In general, shown in Fig. 3, no visible crack was observed in specimens with positive damage level, and small cracks could be seen near the middle of columns for preload levels of $100 \%$, and $-85 \%$. Significant cracks and damage were clearly seen in specimens for preload level of $-75 \%$, and the concrete at top and bottom are spalling seriously. 


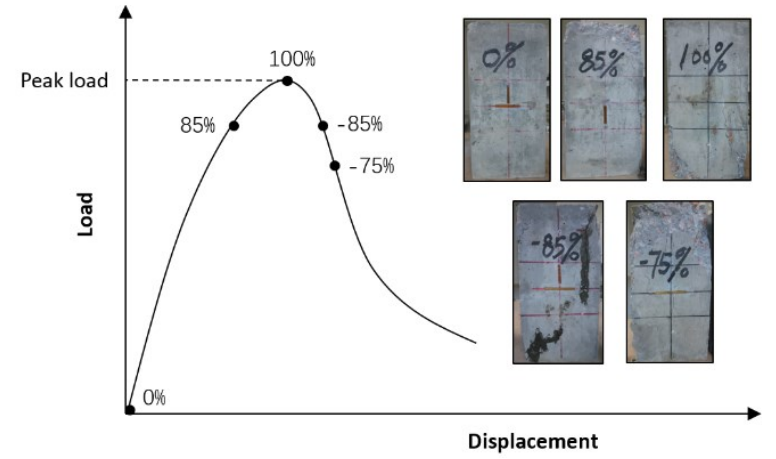

Fig. 3 Pre-load level

\subsection{Materials and specimen repairing}

The 28-days average compressive cylinder strength were $35.1 \mathrm{MPa}$, whereas the concrete strength was 43.8 at the time of actual testing. A unidirectional CFRP with thickness $0.167 \mathrm{~mm}$ was applied in the hoop direction in a wet lay-up manner. The full CFRP sheets with an overlap of $150 \mathrm{~mm}$ were wrapped onto the column surface and a two-part Lica-100 epoxy impregnation resin was used as the adhesive. The material properties of the CFRP were obtained from coupon testing, and the measured ultimate tensile strength, elastic modulus and the ultimate elongation of the CFRP were $4067 \mathrm{MPa}, 273 \mathrm{GPa}$, and $1.49 \%$, respectively.

\subsection{Instrumentation and Testing}
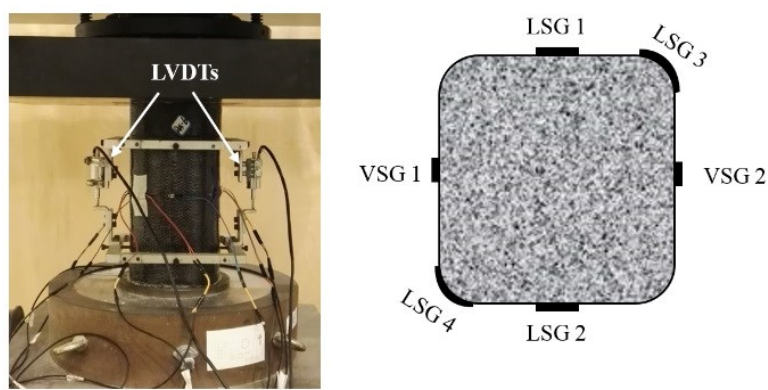

Fig. 4 Setup and strain gauges distribution

For each specimen, strain gauges with a 10 -mm gauge length were attached to the FRP at the mid-height level of the specimen, to measure the axial strain and hoop strain. Figure 4 shows the test set up and the locations of the strain gauges, where VSG and LSG indicate vertical and lateral strain gauges, respectively. During testing, the axial deformation of the specimens was also measured by two longitudinally oriented linear variable differential transformers (LVDTs) that were fixed to an aluminous frame, to obtain the axial deformation of the $180-\mathrm{mm}$ midheight region of the specimen. Specimens were tested under concentric compression loading using the MTS rock machine with a maximum load capacity of $3000 \mathrm{kN}$. For FRP-strengthened specimens, a load rate of $2 \mathrm{kN} / \mathrm{s}$ was applied first for the initial elastic portion until around $70 \%$ of unconfined concrete strength was reached. The loading was then changed to displacement control with a rate of $0.1 \mathrm{~mm} / \mathrm{min}$ until specimen failure.

\section{Test results and data analyses}

Table 1. Test results

\begin{tabular}{ccccccc}
\hline $2 r / b$ & $\begin{array}{c}\text { Damage } \\
\text { level (\%) }\end{array}$ & $\begin{array}{c}\text { plies } \\
\text { ple }\end{array}$ & $\begin{array}{c}\varepsilon_{h, r u p} \\
(\%)\end{array}$ & $\delta$ & $\begin{array}{c}\varepsilon_{c u} \\
(\%)\end{array}$ & $\begin{array}{c}f_{c u} \\
(\mathrm{MPa})\end{array}$ \\
\hline 0.2 & 0 & 2 & 0.44 & 0.00 & 1.18 & 66.7 \\
0.2 & 85 & 2 & 0.39 & 0.03 & 0.74 & 63.0 \\
0.2 & 85 & 2 & 0.38 & 0.03 & 0.70 & 61.3 \\
0.2 & 100 & 2 & 0.35 & 0.08 & 0.74 & 65.4 \\
0.2 & 100 & 2 & 0.40 & 0.16 & 1.23 & 55.4 \\
0.2 & -85 & 2 & 0.30 & 0.16 & 0.70 & 56.9 \\
0.2 & -75 & 2 & 0.41 & 0.35 & 1.27 & 53.2 \\
0.2 & -75 & 2 & 0.41 & 0.35 & 1.23 & 53.3 \\
0.2 & -75 & 2 & 0.37 & 0.35 & 1.45 & 49.2 \\
0.4 & 0 & 2 & 0.54 & 0.00 & 1.16 & 76.4 \\
0.4 & 0 & 2 & 0.40 & 0.00 & 0.68 & 76.6 \\
0.4 & 85 & 2 & 0.52 & 0.03 & 1.02 & 74.2 \\
0.4 & 100 & 2 & 0.42 & 0.08 & 1.04 & 72.7 \\
0.4 & 100 & 2 & 0.56 & 0.08 & 1.23 & 76.7 \\
0.4 & -85 & 2 & 0.32 & 0.16 & 0.56 & 64.4 \\
0.4 & -85 & 2 & 0.45 & 0.16 & 1.02 & 69.5 \\
0.4 & -75 & 2 & 0.39 & 0.35 & 1.27 & 64.6 \\
0.4 & -75 & 2 & 0.33 & 0.35 & 0.92 & 66.0 \\
0.6 & 0 & 2 & 0.57 & 0.00 & 1.11 & 87.0 \\
0.6 & 0 & 2 & 0.49 & 0.00 & 1.08 & 90.8 \\
0.6 & 85 & 2 & 0.58 & 0.03 & 1.14 & 83.9 \\
0.6 & 85 & 2 & 0.57 & 0.03 & 1.13 & 85.1 \\
0.6 & 100 & 2 & 0.44 & 0.08 & 1.00 & 82.7 \\
0.6 & 100 & 2 & 0.45 & 0.08 & 1.02 & 87.9 \\
0.6 & 100 & 2 & 0.55 & 0.08 & 1.45 & 82.7 \\
0.6 & -85 & 2 & 0.58 & 0.16 & 0.94 & 78.5 \\
0.6 & -85 & 2 & 0.50 & 0.16 & 1.17 & 83.5 \\
0.6 & -85 & 2 & 0.40 & 0.16 & 0.76 & 72.3 \\
0.6 & -75 & 2 & 0.41 & 0.35 & 0.92 & 63.7 \\
0.6 & -75 & 2 & 0.45 & 0.35 & 1.55 & 67.0 \\
0.2 & 100 & 3 & 0.38 & 0.08 & 1.02 & 71.2 \\
0.4 & 100 & 3 & 0.60 & 0.08 & 1.38 & 86.7 \\
0.4 & 100 & 3 & 0.83 & 0.08 & 1.19 & 80.2 \\
0.6 & 100 & 3 & 0.58 & 0.08 & 1.47 & 107.0 \\
0.6 & 100 & 3 & 0.70 & 0.08 & 1.56 & 108.4 \\
\hline & & & & & &
\end{tabular}

\subsection{Failure modes}

Figure 5 shows the typical failure model for FRP-confined specimen with the corner radius with 15,30 , and $45 \mathrm{~mm}$, the failure of these specimens was always by CFRP rupture and clicking sounds could be heard during the loading stage, and failure occurred suddenly with an explosive sound. For the concrete specimens with a small 
corner radius, i.e., $r=15 \mathrm{~mm}$, and $30 \mathrm{~mm}$, the fracture of the CFRP jacket was mainly near the corner due to the stress concentration, especially for the specimens with $r$ $=15 \mathrm{~mm}$. For columns with a larger corner radius, i.e., $r=$ $45 \mathrm{~mm}$, the tensile rupture failure mode was similar to that of a column with a circular cross-section that was reported by $\mathrm{Wu}$ et al. [13], the rupture zone is not necessarily occurred at the corner.

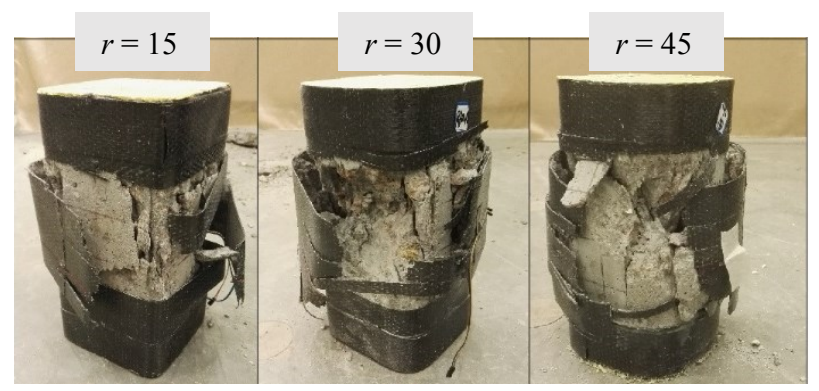

Fig. 5 Typical failure model for FRP-confined specimen with different corner radius

\subsection{Stress-strain responses}

A selection of typical stress-strain curves for each series of specimens is shown in Fig. 6. The axial stress is plotted against the axial and lateral strains, where the axial strains are calculated from the average reading of the two LVDTs divided by the gauge length; the lateral strain is the average value of the four strain gauges that are located at the middle of the side faces and corners of the specimens. Figure 6 shows the comparison of specimens with different damage level but identical corner radius. The results are same to that of the specimens with circular cross-section reported by $\mathrm{Wu}$ et al. [13], the strength of the repaired specimen is lower than those of the undamaged ones, especially for the specimen with damage level $-85,-75$. Furthermore, it is also noted that the initial stiffness of repaired specimen with high damage level can be significantly lower than that of the undamaged ones. It also can be clearly seen that strength of FRP strengthened concrete columns with larger corner radius are all significantly higher than those of the smaller corner radius one, and the effectiveness of FRP repairing highly depended on the corner radius. Thus, it can be concluded that the corner radius effect is also validated for damaged concrete prisms, and same with undamaged FPR confined concrete the variation of corner radius does influence the confinement effectiveness. The details of these test results are shown in Table 1, it will be then analysed with the experimental results reported by $\mathrm{Wu}$ et al. (2014) which focuses on the behaviour of CFRP confined pre-damaged concrete cylinder where the concrete radius $r$ is $75 \mathrm{~mm}$.
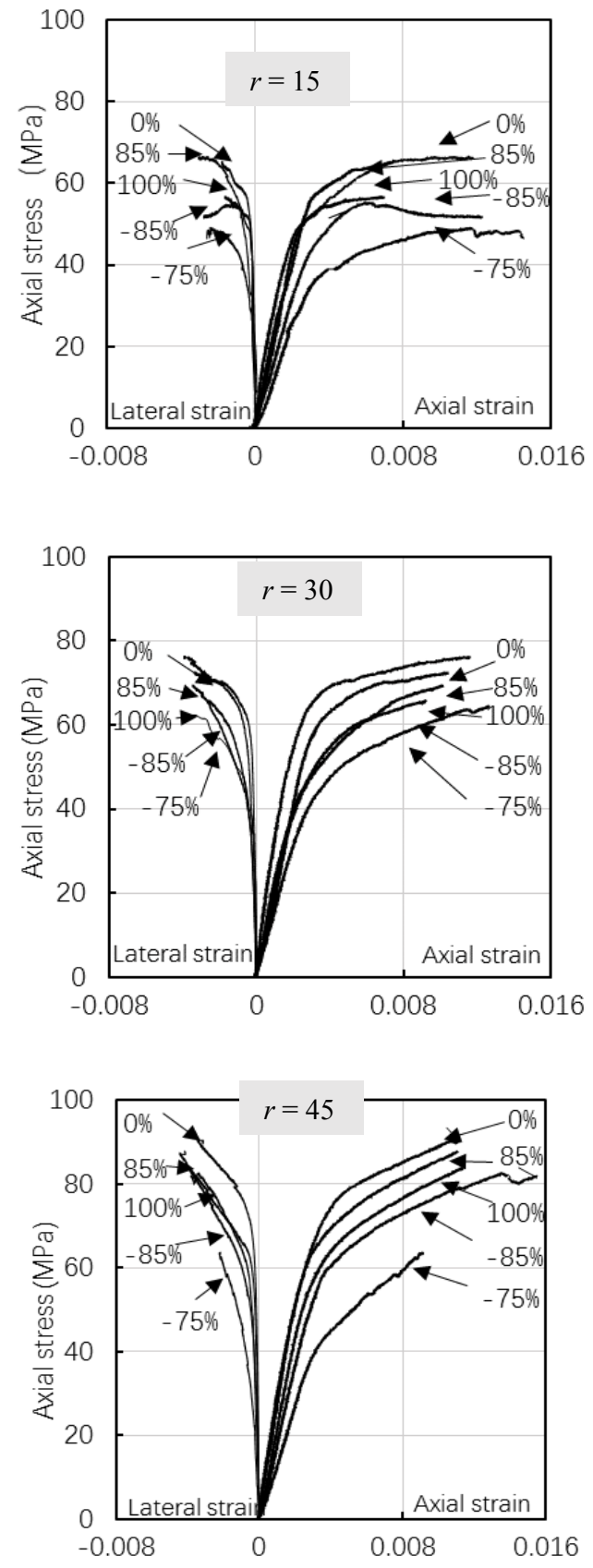

Fig. 6 Stress-strain curves

\subsection{Evaluation of actual damage}

Same with concrete cylinder tested by $\mathrm{Wu}$ et al. [13], the damage level is defined as the drop in relative peak strength to reloading peak strength which are the points $\mathrm{P}$ and $\mathrm{H}$, respectively as shown in Fig. 1. For FRP strengthened specimen, only the unloading point was recorded. Therefore, it is impossible to directly obtain the reloading peak stress by these tests. For specimens without FRP confinement, these data including unloading point and reloading peak strength were recorded. A relationship between reloading peak load and strength reduction factor can be established according to the method proposed by Wu et al. [13], as shown in Fig. 7. The actual damage factor in Fig. 7 is given by Eq. (1), and 
the stress excursion is defined as the total excursion (travel) of stress $\lambda$ along the stress-strain curve up to unloading point, given by [13]:

$$
\lambda=\frac{\int_{0}^{f_{c i}}|d \sigma|}{f_{c o}}= \begin{cases}\frac{f_{c i}}{f_{c o}} & \text { when } \varepsilon_{c i} \leq \varepsilon_{c o} \\ 1+\frac{f_{c o}-f_{c i}}{f_{c o}} & \text { when } \varepsilon_{c i}>\varepsilon_{c o}\end{cases}
$$

where $\sigma=$ axial stress; $f_{c i}$ and $\varepsilon_{c i}$ is the unloading stress and corresponding strain at point D as shown in Fig. 1, and $\varepsilon_{c o}$ is the strain at the peak stress. For example, for the pre-damage levels of +85 and $-75, \lambda$ equals $85 \%$ and $125 \%$, respectively. It is noted that for the positive damage level of $+85 \%$, the actual value of $f_{c o}$ is unknown because the unloading point +85 is less than peak strength and the reloading peak strength theoretically is lower than the undamaged peak strength. For this case, the average measured peak strength of specimen in the same group for other damage level is used as the peak stress. Data from this test are plotted together (Fig. 7) with data obtained from Wu et al.'s experiment [13]. It is indicated that the relationship between actual damage factor and stress excursion is identical, it means that for the plain concrete column the relationship between damage level and stress excursion is independent with cross-section of concrete specimen and concrete grade. For FRP strengthened specimen stress excursion is recorded, and the actual damage can be calculated by Fig. 7 , and the calculated actual damage values for all specimens are provided in Table 1 .

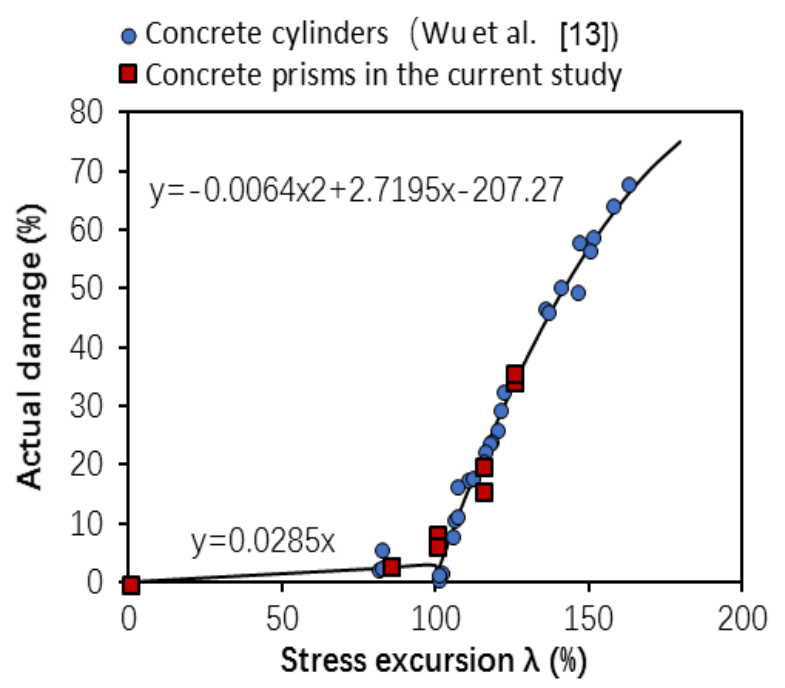

Fig. 7 Actual damage of specimens

\section{Effect of corner radius on damaged ultimate strength}

For pre-damaged FRP confined concrete cylinder, Wu et al. [13] proposed a strength model based on Richart et al' classical model [14] and validates that the model is applicable not only to originally solid concrete but also to damage concrete. Wu et al' s strength model (Wu, et al., 2014) for FRP-confined pre-damaged concrete is described by the following expressions:

$$
\frac{f_{c c}^{\prime}}{f_{c o}}=\frac{f_{c c}}{f_{c o}}-\delta
$$

where

$$
\frac{f_{c c}}{f_{c o}}=1+3.96\left(\frac{f_{l}}{f_{c o}}\right)^{1.13}
$$

where $f_{l}$ is confinement pressure by FRP, and $f_{c c}$ and $f^{\prime}{ }_{c c}$ is the peak strength of FRP confined concrete columns without pre-damage and with pre-damage, respectively. It should be noted that Eq. (3) refers to peak strength $f_{c c}^{\prime}$, which is different from ultimate strength $f_{c u}^{\prime}$ when stressstrain response has a descending branch after the peak strength. Figure 6 shows that the test curves have either strain hardening or softening types of response curves, and hence a new model is required for $f_{c u}^{\prime}$. Moreover, it has been validated that the corner radius ratio $(2 r / b)$ is related to the confinement effectiveness provided by FRP, whereas Eq. (3) is not applicable.

Strengths of all test specimens combined with test results reported by $\mathrm{Wu}$ et al [13] where specimens with corner radius $r=75 \mathrm{~mm}$ are plotted in Fig. 8. Clearly, the strength of the specimens reduces when damage level increases for specimens with all corner radii (Fig. 8), and with the increase of corner radius the strength for all predamage level concrete increase as well (Fig.11b). However, the strength of specimens with same corner radius but different damage levels differ greatly, indicating that existing strength models for FRPretrofitted concrete with different shape of the crosssection cannot cover the strength deviation due to damage. Meanwhile, the strength of specimens with the same damage level but different corner radii also differ significantly, confirming that the strength model derived by $\mathrm{Wu}$ et al. (2014) for FRP-repaired concrete cylinder also cannot reflect the effect of corner radius.

Therefore, based on the model of Eq. (3) proposed by $\mathrm{Wu}$ et al. [13] the ultimate strength model $f_{c u}^{\prime}$ can be mathematically expressed by

$$
\frac{f_{c u}^{\prime}}{f_{c o}}=\frac{f_{c u}}{f_{c o}}-\delta
$$

where

$$
\frac{f_{c u}}{f_{c o}}=1+3.9\left(\frac{f_{l}}{f_{c o}}\right)^{1.13} f\left(\frac{2 r}{b}\right)^{\mu}
$$

after a careful examination of various mathematical functions, the exponential function is found to best fit the trend of Fig. 9. Through a regression analysis with the data points in Fig. 9, $\mu$ is identified to be 0.67 , the strength model is modified, gives:

$$
\frac{f_{c u}^{\prime}}{f_{c o}}=1+3.9\left(\frac{f_{l}}{f_{c o}}\right)^{1.13}\left(\frac{2 r}{b}\right)^{0.67}-\delta
$$

The performance of Eq. (7) is shown in Fig. 10, in which $\mathrm{R}^{2}=0.9$ and the error index $\omega=0.042$, which is defined as: 


$$
\omega=\frac{\sum \mid \text { Exp. }- \text { Theo. } \mid}{\sum \mid \text { Exp. } \mid}
$$

where Theo.=theoretical value given by a model and Exp. $=$ experimental value. For columns with circular crosssection, $2 r / b=1$, Eq. (7) reduce to Eq. (3) proposed by Wu et al. [13] for the pre-damaged concrete cylinder.

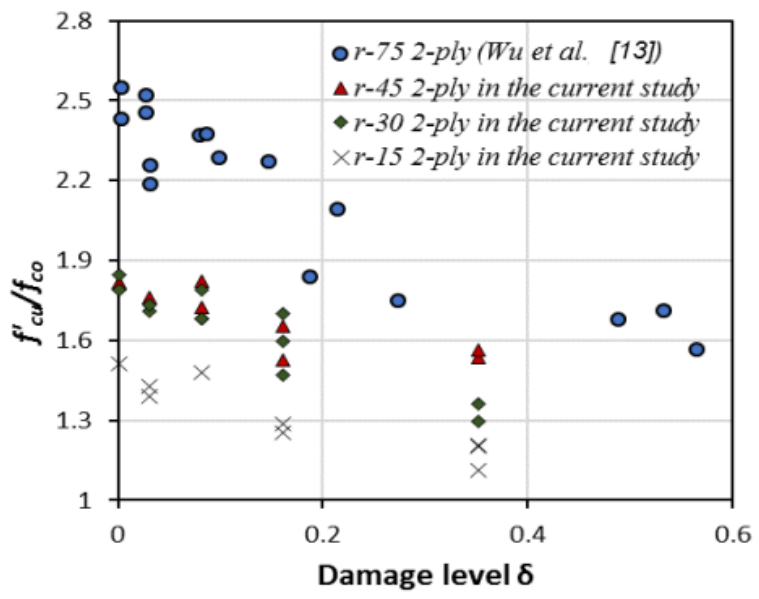

Fig. 8 Effect of damage level on compressive strength

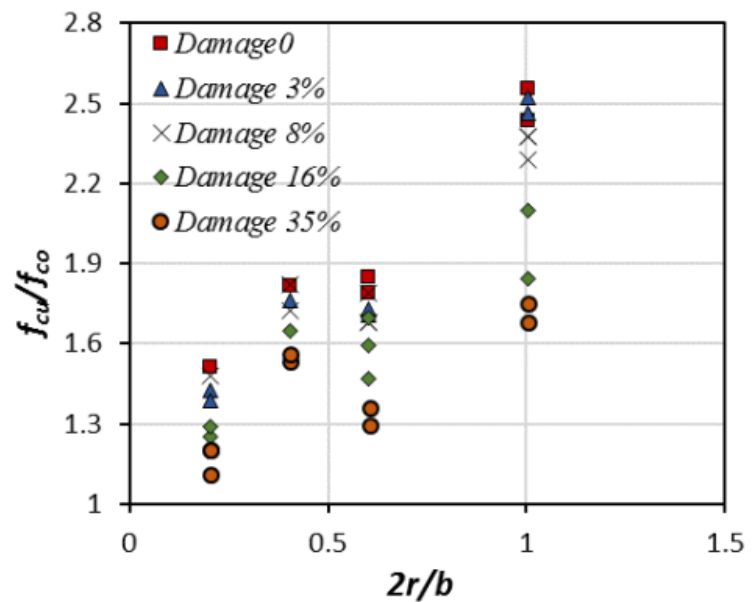

Fig. 9 Effect of corner radius ratio on compressive strength

\section{Effect of corner radius on ultimate strain}

For pre-damaged concrete cylinder, $\mathrm{Wu}$ et al. [13], based on their test results, proposed an empirical model for predicting the ultimate strain $\varepsilon_{c u}^{\prime}$ for FRP confined predamaged concrete cylinder, which is given by:

$$
\frac{\varepsilon_{c u}^{\prime}}{\varepsilon_{c u}}=1-0.3\left(\frac{f_{c o}}{f_{30}}\right)^{2.82} \delta^{0.67}+0.54 \delta
$$

where $\varepsilon_{c u}$ is the ultimate strain when $\delta$ is equal to zero, $f_{30}$ is the concrete strength of unconfined concrete grade C30 concrete. For confined pre-damaged concrete column with varied corner radius, the relationship between ultimate strain ratio $\left(\dot{\varepsilon}_{c u} / \varepsilon_{c u}\right)$ and damage factor $\delta$ is shown in Fig. 11. It is interesting to note that the ultimate strain ratio of specimens with less damage $(0<\delta<0.2)$ is almost constant that reach around 0.8 .

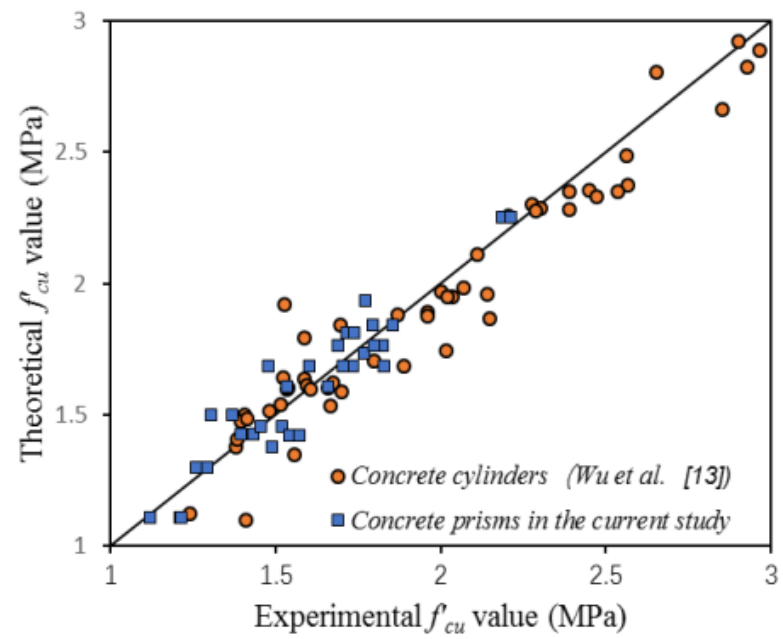

Fig. 10 Performance of proposed ultimate strength model

However, with increasing damage level $(\delta>0.2)$, the specimen with smaller corner radius ratio shows a higher ultimate strain ratio $\left(\varepsilon_{c u}^{\prime} / \varepsilon_{c u}\right)$, and it means that the existing damage can offset the lost confinement effectiveness caused by small corner radius, and this effect is more significant for specimens with a smaller corner radius $(r=15 \mathrm{~mm})$. This test result is unexpected because the previous researcher has reported that the small corner radius can reduce the ultimate strain of FRPconfined concrete column [12], and the FRP confinement effectiveness is reduced by smaller corner radius. After a careful inspection of specimen failure mode, it is found that the increased cracks located at corner for server damaged concrete reduce the sharpness of the corner part, and it avoided cutting the wrapped FRP at the early stage. Hence, for the same corner radius, the ultimate strain ratio for the damaged specimen is larger compared with specimen without damage. Based on the test points shown in Fig. 11, and through extensive regression analyses, the following relationship is found to best fit the experimental results

$$
\frac{\varepsilon_{c u}^{\prime}}{\varepsilon_{c u}}=\left(1-0.3\left(\frac{f_{c o}}{f_{30}}\right)^{2.82} \delta^{0.67}+0.54 \delta\right)\left(\frac{2 r}{b}\right)^{-0.35 \delta}
$$

where, for specimens with circular cross-section $(2 r / b=1)$, the Eq. (10) reduce to Eq. (9). The performance of Eq. (10) is shown in Fig. 12, which also includes the test result for pre-damaged concrete cylinder reported by $\mathrm{Wu}$ et al. [13], in which $\mathrm{R}^{2}=0.82$ and the error index $\omega=0.11$. Scattering of strain measurement is usually large in experimental investigations due to the local nature of strain measurement and the non-uniform local cracking of concrete. This is the reason for the relatively larger fluctuation and scattering of the CFRP strain measurements as compared with other measurements. 


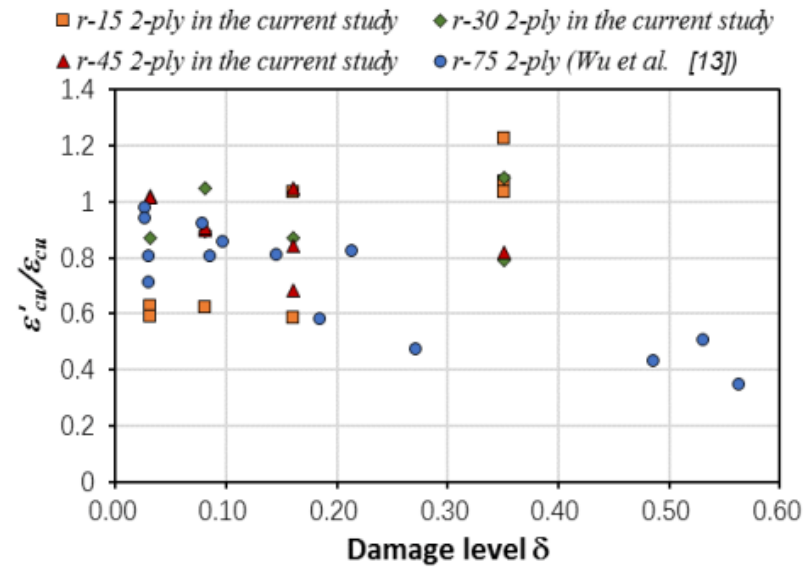

Fig. 11 Effect of damage level on ultimate strain

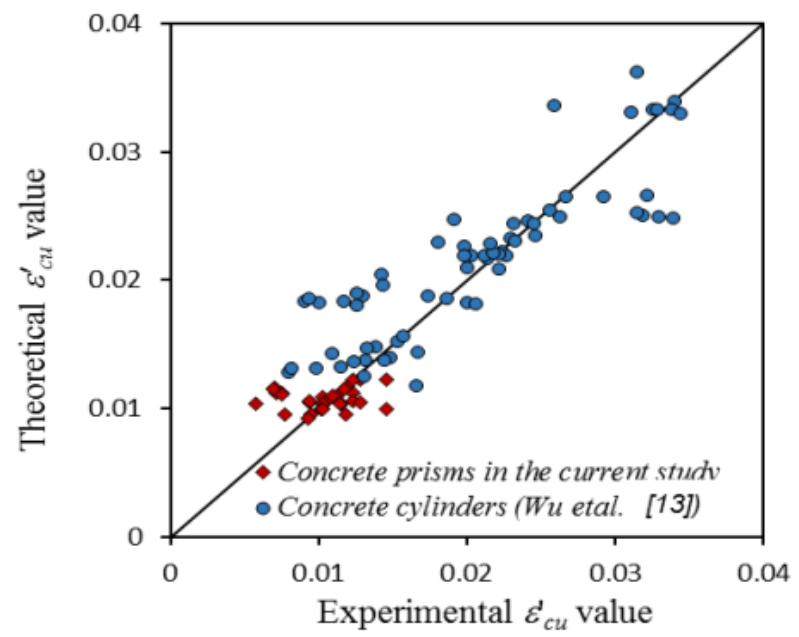

Fig. 12 Performance of ultimate strain model

\section{Conclusions}

Through experimental and analytical studies, the corner radius ratio effect on the stress-strain behaviour of FRP repaired pre-damaged concrete column were investigated, and models for strength, deformation capacity were developed. The strength grain of FRP confined predamaged concrete column is in direct proportion to the corner radius ratio. The ultimate strength of FRP repaired concrete column decreases with the corner radius reduces, and this corner radius effect gradually decreases with the increase of pre-damage level. However, the variation of corner radius has little effect on the ultimate strain ratio $\left(\varepsilon_{c u}^{\prime} / \varepsilon_{c u}\right)$ when the damage level is low $(\delta<0.2)$, however, the corner radius effect is significant for ultimate strain ratio with higher damage levels. It is because that the existing cracks (severe pre-damage) at the corner part reduce the sharpness of corner, and it avoided cutting the wrapped FRP.

The work described in this paper was financially supported by the National Natural Science Foundation of China (Grants No. 51622808, 51578337, 51578338, and 51778371) and the
Shenzhen basic research project (Grant No. JCYJ20170817100253542), to which the authors are grateful.

\section{References}

1. R. D. Iacobucci, S. A. Sheikh, O. Bayrak, ACI Struct. J., 100(6), 785-794. (2003)

2. G. Li, S. Hedlund, S. Pang, W. Alaywan, J. Eggers, C. Abadie, Compos. Part B: Eng., 34(3), 261-271. (2003)

3. L. Van Den Einde, L. Zhao, F. Seible, Constr. Build. Mater., 17(6), 389-403. (2003)

4. P. Li, and Y. F. Wu, Compos. Struct. 134, 60-71. (2015)

5. J. G. Dai, Y. L. Bai, J. G. Teng, J. Compos. for Constr., 15(6), 963-973. (2011)

6. J. G. Teng, T. Jiang, L. Lam, Y. Z. Luo, J. Compos. Constr., 13(4), 269-278. (2009)

7. P. Rochette, P. Labossiere, J. Compos. constr., 4(3), 129-136. (2000)

8. Y. Zhou, X. Liu, F. Xing, H. Cui, L. Sui, Constr. and Build. Mater., 119, 1-15. (2016).

9. S. A. Sheikh, G. Yau, ACI Struct. J., 99(1), 72-80. (2002)

10. A. Mirmiran, M. Shahawy, M. Samaan, H. E. Echary, J. C. Mastrapa, O. Pico, J. Compos. Constr., 2(4), 175-185. (1998)

11. Y. F. Wu, T. Liu, D. J. Oehlers, Adv. Struct. Eng., 9(4), 507-533. (2006)

12. L. M. Wang, Y. F. Wu, Eng. Struct., 30(2), 493-505. (2008)

13. Y. F. Wu, Y. Yun, Y. Wei, Y. Zhou, J. Struct. Eng., 140(12), 04014093. (2014)

14. F. E. Richart, A. Brandtzaeg, R. L. Brown, University of Illinois Bulletin; v. 26, no. 12. (1928) 